\title{
Vulvar Biopsy Patient
}

National Cancer Institute

\section{Source}

National Cancer Institute. Vulvar Biopsy Patient. NCI Thesaurus. Code C156044.

A patient who had or will have a vulva biopsy. 